\title{
An Empirical Study of the Effect of Multimedia Information Technology on College English Teaching
}

DOI: https://doi.org/10.47175/rielsj.v1i1.30

\section{| Xiaoyu Luo ${ }^{1, *} \mid$ Shawn P. Daly ${ }^{2}$ Langfan Wen ${ }^{3}$ |}

\author{
${ }^{1}$ Associate Professor, Foreign \\ Languages School, Hunan \\ University of Technology and \\ Business, China \\ 2 Professor of International \\ Business Former Dean, College \\ of Business, Niagara \\ University \\ ${ }^{3}$ Full Professor, Foreign \\ Languages School, Hunan \\ University of Technology and \\ Business, China \\ ${ }^{*}$ Corresponding Email: \\ cathyluo1981@gmail.com
}

\begin{abstract}
In college English teaching, educators often use multimedia information technology to carry out teaching activities and present the corresponding curriculum content in detail. Based on two semesters of analysis and investigation, this paper presents an empirical study on multimedia teaching in two courses of a non-English major in one Chinese college. The results show that multimedia teaching technology can effectively enhance college students' interest in English learning, stimulate their enthusiasm, enhance the interaction between teachers and students, and cultivate their autonomous learning ability. The research suggests that colleges and universities should strengthen the hardware support and software facilities of multimedia-assisted teaching to promote the significant improvement of students' language ability. KEYWORDS

Multimedia teaching technology; college english; teaching effect
\end{abstract}

\section{INTRODUCTION}

Modern information technology equipment allows multimedia teaching to be easily applied to the college English classroom. Audio, video, and image animation creates an exciting classroom atmosphere, presents interesting teaching content, and stimulates students' interest. In this way, students are more likely to become familiar with the curriculum content. Based on constructivist teaching theory and the modern information technology environment, most teachers employ computer-aided teaching software, and some use multimedia software to produce teaching electronic courseware as an aid in teaching.

Figure 1 demonstrates the basic framework of teaching, whereby the subject (teacher) and object (student) of teaching activity combine because of modern information technology (Huang \& Song, 2012). An empirical analysis follows of the impact of multimedia information technology and its validity on College English Learning demonstrate the connection between technology and knowledge acquisition in practice.

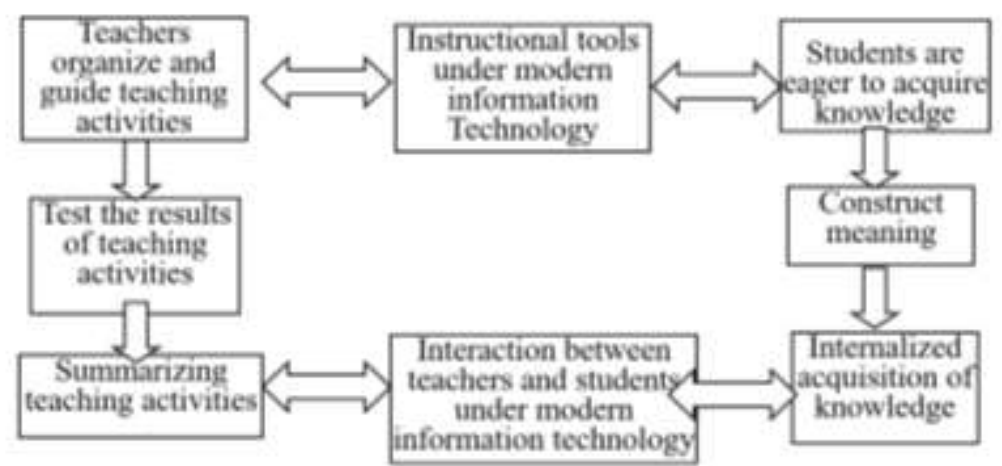

Figure 1. Framework of College English Teaching with Modern Information Technology 


\section{RESEARCH METHODS}

By searching key words "multimedia teaching", "College English" and "empirical research", a total of 1200 papers were collected from China National Knowledge Infrastructure (CNKI), China Library Information Retrieval Center, and other systems. From this search, 1022 papers were seen as the sample in this research, while 78 invalid papers were deleted due to timeliness, inaccuracy and genre (conference papers). This study carried out data comparison and summary analysis on the above papers, and accumulated literature materials for the research.

Considering the specialty of multimedia technology and the practicability of college students' English education, five experts in English education and five experts in the field of multimedia teaching were consulted on relevant issues, including the essence of multimedia teaching technology and evaluation methods of effect. After the interviews, the questionnaire was organized into specialized summary documents and timely arranged and filed.

The questionnaire design not only included the students' gender, grade, personal information, and English level, but also included the current situation of English teaching, the influence of multimedia education on English learning, comparative experiment measurement, open-ended questions and other contents. The questionnaire mainly adopted semi-open design, with 20 items created. All survey data were analyzed.

The analysis was carried out a comparative experiment from two aspects: the exam papers were designed uniformly by the teaching and research department, and the specific question types were basically the same with post-test. Two classes were assessed by examination at the end of two semesters so as to analyze the impact of multimedia teaching technology on college English teaching.

\section{RESULTS}

After two semesters of analysis and investigation, we have conducted a comprehensive study of the above data. The results show there is a difference between multimedia teaching effect and traditional teaching effect.

\section{Test scores}

\section{Pre-test scores}

In the pre-class preparation stage, students were divided into 10 independent groups and formed into WeChat groups. Relevant learning materials were uploaded into WeChat group, as well as 10 self-study tasks related to multimedia teaching. This includes explaining unit themes, understanding long and difficult sentences, understanding sentence knowledge points, recognizing knowledge background design, and clarifying situational dialogues. Two groups of members received knowledge tasks for preview, completing the relevant pre-class homework. Each group discussed with each other, and learned, mastered and consolidated the knowledge through scene reproduction and group debate. But at the stage of classroom teaching, the experimental group teachers used multimedia to teach in the experimental class, which accounted for about one third of the entire classroom time.

The results show the average score of the control class was 71.251, and that of the experimental class was 70.965. In the independent sample test based on data analysis, $\mathrm{t}=0.521$, and its significance level was $\mathrm{p}>0.05$. The result shows the pre-test score exhibited no significant difference between the experiment and control groups. Thus, the relevant experimental analyses can be conducted (Table 1). 
Table 1. Independent Sample pre-test for the Experimental and Control Groups

\begin{tabular}{llllll}
\hline & Headcount & $\begin{array}{l}\text { Mean } \\
\text { score }\end{array}$ & $\begin{array}{l}\text { Standard } \\
\text { deviation }\end{array}$ & $\boldsymbol{t}$-value & $\boldsymbol{p}$-value \\
\hline Experimental group & 44 & 70.965 & 11.821 & 0.521 & 0.618 \\
Control group & 42 & 71.251 & 11.65 & & \\
\hline
\end{tabular}

\section{Post-test results}

After two semesters of the multimedia technology teaching experiment, final exam score in the last semester was selected as the post-test. SPSS17.0 was used for the analysis in this paper. The statistical results show that the average score of the experimental class was 76.416, whereas the average score of the control class was 71.284. The significance level is $\mathrm{p}<0.05$, indicating that the difference was statistically significant. Thus, the application of multimedia teaching technology made a substantial different on student learning over traditional teaching tools (Table 2).

Table 2. Independent Sample Post-Test for the Experimental and Control Groups

\begin{tabular}{llllll}
\hline & Headcount & Mean score & $\begin{array}{l}\text { Standard } \\
\text { deviation }\end{array}$ & $\boldsymbol{t}$-value & $\boldsymbol{p}$-value \\
\hline Experimental group & 44 & 76.416 & 12.394 & 0.631 & 0.047 \\
Control group & 42 & 71.284 & 10.412 & & \\
\hline
\end{tabular}

\section{DISCUSSION}

\section{Analysis of students' identification attitude towards multimedia teaching}

A total of 45 questionnaires were collected. Among them, 40 students clearly preferred multimedia teaching $(90.4 \%)$. According to the questionnaire, nineteen of the respondents believed that teachers and students had more communication under multimedia teaching technology; but nine students held that the communication between teachers and students would be less in the multimedia teaching process. Thirty students thought the application of multimedia information technology was of great help in improving the level of classroom visualization; but six students thought students focused on the screen and had no time to take teachers' expression into account after introducing information technology -resulting in less psychological and emotional communication between teachers and students.

The demographic data showed that students who support multimedia teaching had better academic performance. Similarly, students who disapproved of multimedia teaching had limited English knowledge and weak self-control and self-study ability. One might say that these students do not accept teachers' guidance in university classroom, which led to some emotional resistance. According to the survey, $41.2 \%$ of the students in the experimental class had a strong interest in English learning (especially English learning through multimedia teaching), which was only $14.7 \%$ in the control class. But in the experimental class, $11 \%$ of the students were not interested in multimedia teaching, while $22.4 \%$ of the control class held the opposite attitude.

\section{Analysis of the influence of multimedia teaching on language competence}

The survey shows that after two semesters of English learning under multimedia information technology, students in the experimental group performed better than the control group in English language listening, reading, and speaking - but there was not much difference between the two classes in translation, writing, etc. This shows that college English classes based on multimedia teaching have certain advantages in improving students' basic English ability. 
There were significant differences between the experimental and control groups in language ability, accuracy, application level, reaction ability and reaction consciousness. It can be seen that multimedia teaching significantly improved the English learning performance of college students. Compared with the simple classroom teaching in the past, multimedia teaching can greatly enhance students' interest, activate students' motivation, improve their language sense effectively, and provide effective help for the improvement of their overall language ability.

Interestingly, $49.4 \%$ of the students in the experimental class showed a positive pattern in the process of grade feedback evaluation. In the control class, only $37.8 \%$ of the students had positive feedback on the score.

\section{Analysis of teacher-student interaction and classroom performance under multimedia teaching}

The survey also showed that students' sense of identity and belonging to English classroom under multimedia information technology gradually increased, and the factors such as the sense of identity to multimedia information technology can effectively match classroom performance. The average values of the above items were between 2 and 3, and with no excessive deviation. The standard deviations of the items were within the normal range. The CR values of the above two kinds of analysis were in accordance with the normal range standard. Thus, there is no significant difference between the experimental class and the control class on the above two analyses.

Most college students can effectively communicate and interact with English teachers in their classes. From the perspective of teacher-student interaction, in college English teaching with multimedia, importance is attached to the content presentation, which might ignore human and emotional communication among teachers and students, thereby changing students' psychological motivation. But in fact, in the class supported by multimedia information technology, interaction among teachers and students is more humanized, which can stimulates students' interest, mobilizes students' attitude change towards English learning, and makes up for the teaching lag caused by a single teaching method. In other words, with the help of multimedia information technology, college English teaching contents are vividly presented, which greatly promotes the students to better understand the level of the teacher's teaching setup.

\section{CONCLUSION}

Multimedia teaching can enhance college students' interest in English learning, stimulate their enthusiasm, build interaction between teachers and students, and cultivate their independent learning ability. Therefore, in college English teaching in China, educators should gradually strengthen the hardware support of multimedia information technologyassisted instruction and continue to increase investment into related multimedia information software facilities. By introducing, cooperating deeply, and developing independently teaching settings with multimedia information technology, teaching in college English can be improved continuously, and the students' English ability can be effectively improved.

\section{FUNDING}

This work was supported by the Hunan Province Education Scientific Research Project Grant XJT (2019) No.291 (724), the Hunan Province education scientific research project Grant No. 15B058, Science Fund of Hunan Province No. 16WLH07 and Hunan Province education science planning issues No. XJK168YY07. 


\section{REFERENCES}

Gao, H.L. (2018). Exploring the Normalization of Computer Multimedia Teaching: An Empirical Study Based on College English Multimedia Teaching [J]. China Educational Technology. Vol. 2, p. 25-26. In Chinese.

He, F, Xia W.H. \& He, Y. (2016). Research on Mixed Teaching Mode of College English Based on MOOC. Educational Theory and Practice. Vol. 18, p. 54. In Chinese.

Huang, R.Y. \& Song T.H. (2012). Research on College English Teaching Model in Agricultural and Forestry Colleges Based on Flipped Classroom. Education Theory and Practice. Vol. 30, p. 67. In Chinese.

Luo, X.Y. \& Daly, S.P. (2019). Human capital and English language proficiency in the Chinese context. Asian Social Science 15(3). DOI: 10.5539/ass.v15n3p73.

Wang, Y. (2018). Several Common Theories of Multimedia College English Teaching and Research. China Educational Technology Equipment. Vol. 8, p. 43. In Chinese.

Wu, S.Q. (2016). Task-based College English Flipped Classroom Teaching Model Research. Modern Educational Technology. Vol. 9, p. 19-21. In Chinese. 